\title{
MACRODINÂMICA DO PRODUTO SOB RESTRIÇÃO EXTERNA: A EXPERIÊNCIA BRASILEIRA NO PERÍODO 1930-2004*
}

\author{
Gilberto Tadeu Lima ${ }^{\S}$ \\ Veridiana Ramos Carvalho
}

\begin{abstract}
RESUMO
O artigo analisa o comportamento do produto e da renda agregada no Brasil ao longo do período compreendido entre 1930 e 2004, com que pretende contribuir para o alargamento do horizonte de compreensão das restrições que se interpõem, para além do curto e médio prazos, à obtenção e sustentação de níveis elevados dessas variáveis. O estudo empírico realizado neste artigo detectou que, de uma perspectiva de longo prazo, a produção e a renda nacionais têm sido determinadas essencialmente pelas condições associadas ao equilíbrio das contas externas.
\end{abstract}

Palavras-chave: produto, renda, restrições externas.

\begin{abstract}
The paper analyses the behavior of output and income in Brazil in the 1930-2004 period, thus intending to contribute to a better understanding of the constraints that have been faced by the Brazilian economy to achieve high levels of these variables in the long run. The empirical study developed in this paper revealed that long-run levels of output and income in Brazil have been mostly determined by conditions associated with the external equilibrium of the economy.
\end{abstract}

Keywords: output, income, external constraints.

JEL classification: E10, E23, O11.

\footnotetext{
* Cabem agradecimentos - acompanhados das isenções de praxe - a Edmar Bacha e a um parecerista anônimo.

$\S$ Professor do Departamento de Economia da FEA-USP. O autor agradece ao CNPq pelo suporte sob a forma de Bolsa de Produtividade em Pesquisa. E-mail: giltadeu@usp.br.

a Doutoranda em Teoria Econômica no IPE-FEA-USP. E-mail: vrc@usp.br.

Endereço para contato: Departamento de Economia da FEA-USP - Av. Prof. Luciano Gualberto, 908 - CEP: 05508-900 - São Paulo - SP.

Recebido em junho de 2007. Aceito para publicação em março de 2008.
} 


\section{INTRODUÇÃO}

O presente artigo aborda, de uma perspectiva essencialmente empírica, o comportamento do produto e da renda no Brasil no período compreendido entre 1930 e 2004, com que se pretende contribuir para o alargamento do horizonte de compreensão das restrições que se interpõem, para além do curto e médio prazos, à obtenção e, principalmente, à sustentação de níveis elevados dessas variáveis. Colocando de maneira direta, o estudo empírico que será reportado neste artigo detectou que, de uma perspectiva de longo prazo, a produção e a renda nacionais têm sido determinadas essencialmente pelas condições associadas ao equilíbrio das contas externas. Propõe-se, portanto, que a restrição externa tem configurado o principal fator limitante do crescimento econômico brasileiro, quando o horizonte de observação vai além do curto e médio prazos.

Muito embora a intenção principal deste artigo não seja analisar especificamente a acentuada inflexão - para baixo - experimentada pela tendência do crescimento brasileiro no início da década de 1980, espera-se que a avaliação empírica reportada e comentada a seguir amplie o entendimento dos determinantes dessa tendência declinante que se prolongou até o início da década de 1990 - e, cabe lembrar, não se transformou em ascendente mesmo na década seguinte à estabilização monetária alcançada e mantida a partir de meados de 1994. Com efeito, a economia brasileira, após ter crescido à taxa média anual de 6,8\% no período compreendido entre 1932 e 1980, passou então a crescer à taxa média anual de 2,2\% no período entre 1981 e 2004.

Em face disto, uma questão fundamental que imediatamente se coloca diz respeito aos determinantes da perda de dinamismo de crescimento, experimentada pela economia brasileira a partir do início da década de 1980; um dinamismo cuja tendência de queda à estabilização inflacionária lograda a partir de 1994, embora tenha interrompido, não tem sido capaz de inverter. De fato, a economia brasileira, após ter crescido à taxa média anual de 8,5\% no período entre 1970 e 1980 , cresceu à taxa média anual de 2,0\% entre 1981 e 1994 e à taxa média anual de apenas 2,3\% entre 1995 e 2002.

Por outro lado, essa queda no crescimento brasileiro não pode ser vista como característica de um conjunto representativo de países em desenvolvimento. Enquanto o Brasil cresceu à taxa média anual de apenas 2,7\% e 2,6\% nos períodos entre 1980 e 1990 e entre 1990 e 2003, respectivamente, são bastante superiores os números correspondentes para países como Chile $(4,2 \%$ e 5,6\%), Índia (5,7\% e 5,9\%), Irlanda (3,2\% e 7,7\%), Malásia (5,3\% e 5,9\%) e Vietnã (4,6\% e 7,5\%). Em termos de crescimento do produto per capita, por sua vez, as diferenças em relação a outros países em desenvolvimento também são significativas. Enquanto o produto per capita brasileiro cresceu apenas 13,56\% no período entre 1980 e 2000, são bastante superiores os números respectivos para países como Tailândia (148,77\%), Hong Kong (113,35\%), Irlanda (164,36\%) e Coréia (228,84\%).

Uma inovação central do presente artigo em relação à literatura sobre o tema do crescimento econômico sob restrição externa reside na utilização de um teste empírico que, ao analisar as variáveis que se ajustam no curto prazo para promover o equilíbrio de longo prazo do balanço de pagamentos, contribui para confirmar a determinação do produto pela demanda agregada. Vale dizer, com a inclusão de todos os componentes do balanço de pagamentos na equação estimada, o equilíbrio do balanço de pagamentos passa a representar uma identidade de longo prazo - excluindo-se, é claro, a possibilidade de acumulação ilimitada de reservas. Logo, torna-se relevante 
para uma validação mais ampla da hipótese de crescimento sob restrição externa uma análise das variáveis que se ajustam no curto prazo para gerar o equilíbrio de longo prazo.

Conforme a abordagem keynesiana aqui empregada, parte significativa desse ajuste ocorreria via renda interna. A abordagem neoclássica tradicional, por seu turno, indicaria o ajuste via câmbio real, supondo que a renda é determinada exogenamente ao equilíbrio do balanço de pagamentos por fatores em nível de oferta. E uma vez que é possível encontrar uma versão da abordagem neoclássica tradicional, na qual esse ajuste ocorreria por meio das exportações (KRUGMAN, 1989), a análise aqui desenvolvida das variáveis que se ajustam no curto prazo para gerar o equilíbrio de longo prazo é uma maneira adequada de confrontar essas abordagens. Nesse contexto, outra inovação deste artigo reside na realização de uma análise específica de um mecanismo de transmissão entre a restrição externa e o nível de produto que passa pelo comportamento do investimento.

Daí, portanto, a procedência da utilização de técnicas de cointegração na estimação direta de uma versão completa da equação de equilíbrio do balanço de pagamentos. Enquanto o vetor de cointegração fornece a relação de longo prazo existente entre as variáveis de interesse, os coeficientes de ajustamento permitem a análise precisa das variáveis que se ajustam no curto prazo para a convergência para essa relação de longo prazo.

\section{A ABORDAGEM DA RESTRIÇÃO EXTERNA AO CRESCIMENTO ECONÔMICO DE LON- GO PRAZO}

O estudo empírico reportado e comentado a seguir pretendeu estimar em que medida a produção e a renda de longo prazo da economia brasileira têm sido determinadas por condições associadas ao equilíbrio das contas externas. Para tanto, fez-se uso de uma abordagem do crescimento econômico sob restrição externa elaborada pelo economista inglês Anthony Thirlwall, conhecido, entre outros trabalhos, por sua abordagem peculiar sobre os mecanismos por meio dos quais as taxas de crescimento econômico diferem entre os países.

As análises mais convencionais, tipicamente de extração neoclássica, do processo de crescimento econômico focalizam exclusivamente os determinantes da expansão do produto no lado da capacidade de ofertar bens e serviços, ou seja, a acumulação de estoques de capital físico e humano, tecnologia, etc. Por sua vez, Thirlwall propõe considerar-se que, em geral, antes de se exaurir tal potencial de geração do produto de um país, restrições na demanda agregada por bens e serviços apresentam-se como fator de limitação mais significativo.

Além disso, no contexto de economias abertas, Thirlwall assinala que as restrições quanto à disponibilidade de divisas tendem a apresentar-se como o principal obstáculo a níveis mais elevados de demanda agregada. Dado certo estado das artes quanto à competitividade externa de um país, algo que se refletirá em suas exportações e na demanda por importações de bens e serviços, não há como o crescimento econômico escapar da restrição colocada pela circunstância de que os pagamentos em divisas não podem ser, no longo prazo, superiores às receitas em divisas. Os níveis de investimento e outros gastos, no âmbito doméstico, podem até ser manipulados - por políticas fiscal e monetária - de maneira a garantir que a demanda agregada acompanhe o potencial do pro- 
duto. Já a restrição de divisas depende de fatores fora do controle imediato dos gestores da demanda agregada. ${ }^{1}$

O aporte de capital externo, na conta de capitais no balanço de pagamentos, permite que importações de bens e serviços não-fatores possam ser superiores às receitas com exportações. Este déficit será sustentável se e enquanto o ingresso de investimentos diretos e em carteira, empréstimos e financiamentos mantiverem-se superiores aos fluxos no sentido inverso, ou seja, remuneração e repatriação de capital. Contudo, essa entrada líquida de capital não é uma conta bancária de saldo ilimitado, estando sujeita a reavaliações periódicas quanto à solidez dos compromissos de pagamentos externos do país, com isto determinando a margem possível, em cada momento de tempo, para que as importações sejam superiores às vendas externas. E aí, fechando o círculo, os déficits entre os pagamentos referentes às importações e as receitas com exportações não podem ser explosivos.

$\mathrm{Na}$ formulação que se tornou conhecida na literatura como a Lei de Thirlwall, ${ }^{2}$ conforme derivado formalmente a seguir, a taxa de crescimento do país não poderá distanciar-se muito da seguinte conta: a taxa de crescimento do produto mundial multiplicada pela elasticidade-renda das exportações e dividida pela elasticidade-renda das importações. Dado um certo ritmo de crescimento na produção mundial, as vendas externas do país aumentarão conforme a elasticidade-renda das exportações. Por outro lado, essa expansão nas receitas elevará a margem de manobra para o crescimento doméstico apenas na extensão em que for mais ou menos absorvida por elevação das importações, conforme sua elasticidade-renda.

Desde logo, é fundamental esclarecer que a abordagem do crescimento sob restrição externa à Thirlwall, não obstante esteja assentada no pressuposto de que restrições na demanda agregada apresentam-se como fator de limitação mais significativo ao crescimento econômico no longo prazo, não ignora a relevância de fatores associados à oferta agregada. Afinal, as elasticidades-renda associadas ao saldo comercial têm uma natureza à Janus: se, por um lado, são determinantes da demanda agregada, são o reflexo, por outro lado, de uma variedade de fatores em nível de oferta que condicionam a competitividade estrutural da economia. ${ }^{3}$

Evidentemente, a restrição comercial determinada por elasticidades-renda pode vir a ser alterada por mudanças nos patamares da taxa real de câmbio. Entretanto, depreende-se da Lei de Thirlwall que, para um desvio definitivo em relação às elasticidades-renda, a economia teria de apresentar processos de desvalorização ou valorização cambial real permanente. Logo, a competitividade estrutural do país, conforme refletida nas elasticidades-renda de exportações e importações, acaba, por meio destas últimas, determinando seu potencial de crescimento. Daí depreende-se, por conseguinte, a necessidade de melhora na competitividade estrutural brasileira como requisito para maior crescimento.

1 Segundo Thirlwall "[t]here are not many countries in the world, particularly developing countries, that could not utilize (or generate) more domestic resources given the greater availability of foreign exchange... and the fundamental importance of exports as a component of demand is that it is the only component that can provide the foreign exchange to pay for the import content of other components of demand - consumption, investment, and government expenditure." (1997, p. 380; ênfase original).

2 Muito embora o próprio Thirlwall (1997, p. 378) tenha mencionado posteriormente que "fato estilizado" ou "generalização empírica" talvez seja uma melhor descrição que "Lei" para o que veio a ser conhecido como a Lei de Thirlwall.

3 Como assinalado, por exemplo, em McCombie e Thirlwall (1994): "Income elasticities determine the balance-of-payments constrained growth rate, but the supply characteristics of goods (such as their technical sophistication, quality etc.) determine relative income elasticities. In this important respect, there can be a marrying of the demand and supply side explanations of the comparative growth performance of nations." (p. 391). 
Em sua formulação inicial, Thirlwall (1979) assim especifica a condição de equilíbrio externo:

$$
P_{d} X=P_{f} M E
$$

onde $X$ é a quantidade de exportações de bens e serviços não-fatores, $P_{d}$ é o preço das exportações em moeda nacional, $M$ é a quantidade de importações de bens e serviços não-fatores de produção, $P_{f}$ é o preço das importações em moeda estrangeira e $E$ é a taxa de câmbio nominal. Nessa formulação inicial, portanto, o equilíbrio externo envolve somente a balança comercial. Expressando as variáveis da eq. (1) em termos de taxa de crescimento, obtemos:

$$
p_{d}+x=p_{f}+m+e
$$

onde as letras em minúsculo indicam as respectivas taxas de crescimento. Assumindo formas multiplicativas tradicionais, com elasticidades constantes, para as importações e as exportações, obtemos:

$$
\begin{aligned}
& M=a\left(\frac{P_{f} E}{P_{d}}\right)^{\psi} Y^{\pi} \\
& M=a\left(\frac{P_{f} E}{P_{d}}\right)^{\psi} Y^{\pi}
\end{aligned}
$$

onde $a$ e $X$ são constantes positivas, $\psi(<0)$ é a elasticidade-preço da demanda por importações, $\eta(<0)$ é a elasticidade-preço da demanda por exportações, $Y$ é a renda doméstica, $Z$ é o nível da renda mundial, $\pi$ é a elasticidade-renda da demanda por importações, enquanto $\varepsilon$ é a elasticidaderenda da demanda por exportações. Colocando as variáveis das eqs. (3) e (4) em termos de taxa de crescimento, obtemos:

$$
\begin{aligned}
& m=\psi\left(p_{f}+e-p_{d}\right)+\pi y \\
& x=\eta\left(p_{d}-e-p_{f}\right)+\varepsilon z
\end{aligned}
$$

Por meio da substituição das eqs. (5) e (6) na eq. (2), obtemos então a taxa de crescimento restringida pelo equilíbrio externo:

$$
y_{b p}=\frac{(1+\eta+\psi)\left(p_{d}-e-p_{f}\right)+\varepsilon z}{\pi}
$$

Nessa formulação inicial, assim como nas seguintes, Thirlwall (1979) assume que, no longo prazo, a variação nos termos de troca, se alguma é negligenciável, seria, formalmente:

$$
p_{d}=p_{f}+e
$$

Logo, a eq. (7) se reduz a: 


$$
y_{b p}=\frac{x}{\pi}
$$

posto que $x=\varepsilon z$ é a taxa de crescimento das exportações. ${ }^{4}$ Assim sendo, $y_{b p}$ representa a taxa de crescimento do produto consistente com a satisfação da restrição relativa ao estabelecimento do equilíbrio externo.

$\mathrm{Na}$ formulação imediatamente seguinte dessa abordagem, feita agora por Thirlwall e Hussain (1982), assume-se a seguinte especificação para o equilíbrio externo:

$$
P_{d} X+F=P_{f} M E
$$

onde $F$ é o valor nominal dos fluxos de capital medidos em moeda doméstica. Expressando as variáveis na eq. (10) em termos de taxa de crescimento, obtemos:

$$
\theta\left(p_{d}+x\right)+(1-\theta) f=p_{f}+m+e
$$

onde as letras em minúsculo indicam as taxas de crescimento correspondentes, enquanto $\theta$ e $1-\theta$ representam, respectivamente, as frações das exportações e dos fluxos de capital nas receitas externas totais, dadas por $P_{d} X+F$.

Voltando a assumir formas multiplicativas, com elasticidades constantes, para as importações e as exportações, eqs. (3) e (4), bem como a constância dos termos de troca no longo prazo, eq. (8), obtemos:

$$
y_{f}=\frac{\theta x+(1-\theta)\left(f-p_{d}\right)}{\pi}
$$

lembrando que $x=\varepsilon z$. Logo, $y_{f}$ representa a taxa de crescimento do produto doméstico correspondente à satisfação da restrição externa na presença de fluxos de capital. Ou seja, a taxa de crescimento econômico, nesse caso, é igual à soma ponderada entre a taxa de crescimento das exportações e a taxa de crescimento dos fluxos reais de capitais, dividida pela elasticidade-renda da demanda por importações.

4 Como reconheceu Thirlwall, essa expressão para $y_{b p}$ é equivalente a uma versão dinâmica do multiplicador de comércio internacional de Harrod (1933) - do qual, porém, ele alegou que não tinha conhecimento quando de sua derivação da expressão para $y_{b p}$. Thirlwall (1983), por sua vez, mostra que os modelos de desenvolvimento desigual de Prebisch (1950), Seers (1962) e Kaldor (1970), quando reduzidos à sua essência, igualmente associam diferenças entre taxas nacionais de crescimento a diferenças em nível de elasticidades-renda de exportações e importações. Em verdade, a restrição de divisas, ao lado da restrição de poupança, já era parte integrante dos modelos de dois hiatos na tradição de Chenery e Bruno (1962). Na mesma tradição, um modelo de três hiatos, acrescentando um hiato fiscal, é desenvolvido em Bacha (1989 e 1990).

5 Krugman (1989) posteriormente derivou a mesma expressão, chamando-a, porém, sem fazer menção a Thirlwall (1979), de Regra de $45^{\circ}$. Isso não surpreende, dado que Krugman empregou a mesma especificação do equilíbrio externo e as mesmas formas funcionais para o saldo comercial, além de também supor a constância dos termos de troca no longo prazo. Krugman, entretanto, inverte o sentido da causalidade: o crescimento de longo prazo, ao invés de ser endógeno à satisfação da restrição externa, quando esta se interpõe de maneira incontornável, é determinada, à maneira convencional, por fatores associados à oferta (acumulação e produtividade dos fatores de produção), estando a satisfação da Regra de $45^{\circ}$ garantida pelo ajustamento das elasticidades. 
Embora incorpore fluxos de capital, essa versão ampliada de Thirlwall e Hussain (1982) não leva em conta o endividamento externo acumulado, ao qual correspondente pagamento de juros. As várias implicações desse endividamento externo, inicialmente consideradas em McCombie e Thirlwall (1997), recebem um tratamento algo mais completo em Moreno-Brid (1998-99), no qual a taxa de crescimento compatível com o equilíbrio externo é derivada a partir de uma restrição externa que incorpora uma relação estável entre a dívida externa e o produto. Elliot e Rhodd (1999), por seu turno, incorporam endividamento externo e seu serviço ao modelo elaborado em Thirlwall e Hussain (1982), enquanto Moreno-Brid (2003) incorpora o pagamento de juros da dívida externa, cuja não consideração na versão anterior de seu modelo configurava uma séria limitação que já havia sido apontada por Barbosa-Filho (2001). ${ }^{6}$

A abordagem do crescimento sob restrição externa à Thirlwall tem sido suportada por uma variedade de evidências empíricas. Uma amostra dessas evidências inclui: Thirlwall (1979), Bairam (1988), Andersen (1993), McCombie (1997) e Alonso e Garcimartín (1998-99), para grupos de países desenvolvidos; Atesoglu (1997) e Hieke (1997), para os Estados Unidos; Atesoglu (1994), para a Alemanha; León-Ledesma (1999), para a Espanha; Thirlwall e Hussain (1982), Bairam e Dempester (1991) e Perraton (2003), para um grupo de países em desenvolvimento; Hussain (1999), para uma coleção de países africanos; Ansari e Xi (2000), para uma amostra de países do sudeste asiático; Razmi (2005), para a Índia; Lopez e Cruz (2000), Bértola, Higachi e Porcile (2002) e Holland, Vieira e Canuto (2004), para conjuntos de países latino-americanos; Moreno-Brid e Pérez (1999), para uma amostra de países centro-americanos, e Moreno-Brid (1999), para o México.

A primeira avaliação empírica em que houve a inclusão do Brasil nas estimações foi aquela desenvolvida em Thirlwall e Hussain (1982). O estudou concluiu que, no Brasil, entre 1951 e 1969, de um crescimento anual médio de 9,5\%, algo como $4 \%$ pôde ser atribuído à Lei de Thirlwall, conforme a eq. (9), 0,1\% a variações nos termos de troca e, a maior parte, cerca de 5,4\%, a fluxos de capital. Ou seja, a dimensão financeira foi relevante ao longo desse período. Em uma linha semelhante de consideração da conta capital, porém de maneira mais ampla, Ferreira (2001), cobrindo o período entre 1949 e 1999, detectou que o influxo de capitais não aliviou a restrição externa no longo prazo. Em verdade, o estudo concluiu que, ao longo do período, no qual a taxa de crescimento anual média foi de 5,4\%, o pagamento de serviços sobre o capital externo diminuiu a capacidade de crescimento do País em cerca de $1 \%$.

Em seu estudo sobre quatro países latino-americanos (Brasil, Argentina, Colômbia e Chile), ao longo do período entre 1965 e 1996, Lopez e Cruz (2000) encontram evidências em favor da abordagem à Thirlwall para a experiência brasileira. Cabe destacar que o estudo não assume a constância dos termos de troca, encontrando mesmo evidências de sua melhora no período. Por sua vez, o estudo desenvolvido em Bértola, Higachi e Porcile (2002) encontra evidências em favor da Lei de Thirlwall, conforme a eq. (9) anteriormente derivada, para o Brasil no (longo) período entre 1890 e 1973. Ou seja, o estudo não abarcou anos seguintes ao de 1973, a partir do qual os fluxos de capital e o endividamento externo passaram a ter uma importância crescente na determinação do

6 McCombie e Thirlwall (1994) reportam e comentam o estado das artes - no início da década de 1990 - do debate teórico-formal e empírico acerca da abordagem do crescimento sob restrição externa à Thirlwall. Por seu turno, a coletânea organizada por McCombie e Thirlwall (2004) republica vários dos principais artigos dessa literatura - assinados pelo próprio Thirlwall ou não - citados ao longo deste artigo, contando com uma introdução na qual os organizadores sintetizam o estado das artes vigente no início da década de 2000. Uma análise mais atualizada das literaturas teórico-formal e empírica sobre crescimento econômico sob restrição externa à Thirlwall é desenvolvida em Araujo e Lima (2007). 
equilíbrio externo. Novas evidências em favor da abordagem à Thirlwall para a experiência brasileira resultaram do estudo empírico desenvolvido em Jayme Jr. (2003). Para o período transcorrido entre 1955 e 1998, detectou-se a existência de uma relação positiva no longo prazo entre as taxas de crescimento das exportações e do produto.

Por sua vez, Holland, Vieira e Canuto (2004) testam empiricamente a validade da Lei de Thirlwall para a experiência brasileira transcorrida entre 1950 e 2000 - baseando-se, portanto, na eq. (9) derivada anteriormente, a qual desconsidera fluxos de capital e variações nos termos de troca. Foi encontrada uma forte evidência de relação de longo prazo entre o produto, as exportações e as importações. Contudo, a taxa de crescimento efetiva média foi de 5,34\% no período, enquanto a taxa de crescimento prevista pelo modelo estimado pelos autores foi de 3,42\%. Sendo assim, a economia brasileira teria crescido acima do previsto - pela Lei de Thirlwall - em uma extensão que estaria associada a fluxos de capital ou a variações nos termos de intercâmbio.

De fato, o estudo desenvolvido em Santos, Lima e Carvalho (2005), com dados para o período entre 1948 e 2004, encontra evidências da existência de uma restrição externa ao crescimento brasileiro. No entanto, desvios entre a taxa de crescimento real e a prevista pela Lei de Thirlwall parecem estar presentes na experiência, podendo estar associados a fluxos de capital ou a variações nos termos de intercâmbio. O estudo testou dois modelos para o caso brasileiro, a saber, um centrado na Lei de Thirlwall e outro baseado em Moreno-Brid (2003), o qual demonstrou elevado poder explicativo para o caso mexicano, conforme reportado anteriormente. $\mathrm{O}$ instrumental de cointegração foi utilizado na estimativa da elasticidade-renda das importações observada no período entre 1948 e 2004, com o intuito de compará-la com a elasticidade hipotética gerada por aqueles dois modelos. Obteve-se uma elasticidade efetiva de 1,77, enquanto a elasticidade hipotética gerada pelo modelo à Lei de Thirlwall foi de 1,71 e a produzida pelo modelo à Moreno-Brid (2003) foi de 1,80. Por intermédio de um teste específico, verificou-se que não se pode rejeitar a hipótese de que a elasticidade observada é igual à elasticidade gerada pelo modelo à Moreno-Brid (2003). Porém, também não se pode rejeitar a hipótese de que a elasticidade observada é igual à elasticidade produzida pelo modelo à Lei de Thirlwall. Ou seja, embora o estudo também tenha testado uma especificação que incorpora fluxos de capital e variações nos termos de troca, o resultado correspondente pouco diferiu daquele gerado pela especificação à Lei de Thirwall. Sendo assim, pôde-se concluir pela nulidade do resultado líquido da operação conjunta dos efeitos fluxos de capital e termos de troca.

\section{ESTIMAÇÃo EMPÍRICA}

Os estudos empíricos mais recentes da abordagem do crescimento econômico sob restrição externa, especialmente para o caso brasileiro, têm adotado basicamente uma dentre duas metodologias. Uma dessas metodologias foi proposta por McCombie (1989). Basicamente, o autor define a elasticidade-renda hipotética como sendo aquela que iguala a taxa de crescimento observada e a teórica, dada pela eq. (9). Caso essa elasticidade-renda hipotética não seja estatisticamente diferente daquela estimada a partir da função demanda de importações efetiva, não se pode refutar a hipótese de que o crescimento do país é restrito pelo equilíbrio externo. Esse método foi utilizado por Moreno-Brid (1998-99; 2003) para o caso mexicano e, para o caso brasileiro, por Santos, Lima e 
Carvalho (2005). Outros trabalhos, por sua vez, utilizam a própria equação de equilíbrio da conta corrente para testar a Lei de Thirlwall, o que implica estimar a eq. (7), considerando os termos de troca, ou a eq. (9). Para validar a Lei de Thirlwall, o coeficiente dos termos de troca deveria ser insignificante ou, ao menos, pouco significante em relação ao coeficiente da renda externa. Assim, se o coeficiente da renda externa for significante, parte do ajustamento do balanço de pagamentos ocorreria via renda interna, o que confirmaria a visão keynesiana de restrição de demanda ao crescimento econômico. Os testes realizados por Jayme Jr. (2003), Lopez e Cruz (2000) e Bértola, Higachi e Porcile (2002) utilizam essa metodologia.

A metodologia do estudo empírico desenvolvido no âmbito deste artigo se aproxima desta última abordagem, posto que estima diretamente a equação de crescimento compatível com o equilíbrio externo. O presente estudo, porém, inova em relação à literatura empírica sobre a restrição externa ao crescimento econômico brasileiro em várias dimensões. Uma delas diz respeito à inclusão da parte financeira do balanço de pagamentos, sob a forma tanto de entrada de capital como de serviços de fatores. Cabe mencionar que a importância dessa inclusão em uma pesquisa futura já havia sido ressaltada por Bértola, Higachi e Porcile (2002), que a consideram fundamental para a compreensão do processo de crescimento econômico brasileiro entre as décadas de 1970 e 1990. O artigo de Santos, Lima e Carvalho (2005), baseado no modelo de Moreno-Brid (2003), embora considere a conta financeira, tem a limitação de supor uma trajetória constante para a relação Conta Corrente/PIB, a partir da suposição de um limite arbitrário para esta razão, o que não será necessário neste artigo. Além disso, a metodologia utilizada em Santos, Lima e Carvalho (2005), baseada na metodologia de McCombie (1989), que propõe estimar a função de importação e não a própria equação de equilíbrio externo, impossibilita o uso do instrumental econométrico de cointegração - e não apenas da relação de longo prazo, mas também da dinâmica de curto prazo, como foi feito, sem a inclusão da parte financeira (fluxo de capitais e serviço da dívida), entretanto, por Bértola, Higachi e Porcile (2002). Logo, a diferença fundamental do presente estudo empírico em relação àquele desenvolvido em Santos, Lima e Carvalho (2005) é que este último não analisa a dinâmica de ajuste do balanço de pagamentos, uma vez que estima uma função de importação e não uma equação de equilibrio externo. Por outro lado, enquanto em Santos, Lima e Carvalho (2005) o objeto de análise é o comportamento da taxa de crescimento do produto ao longo do período entre 1948 e 2004, no presente estudo esse objeto é o comportamento do nível de produto no período 1930-2004. Adicionalmente, o presente artigo inova em relação ao conjunto da literatura existente ao testar empiricamente um certo mecanismo de transmissão entre o setor externo e o crescimento econômico no Brasil.

Colocando de outra forma, quando todos os componentes do balanço de pagamentos estão incluídos na equação estimada, como é o caso do presente estudo empírico, esta passa a representar uma identidade de longo prazo - excluindo-se, é claro, a possibilidade de acumulação ilimitada de reservas. Logo, torna-se necessária para a validação da hipótese de crescimento sob restrição externa, na forma da Lei de Thirlwall, a análise das variáveis que se ajustam no curto prazo para gerar o equilíbrio de longo prazo do balanço de pagamentos. Segundo a abordagem keynesiana aqui desenvolvida, parte significativa desse ajuste ocorreria via renda interna. A abordagem neoclássica tradicional, por sua vez, indicaria o ajuste via câmbio real, no suposto de que a renda é determinada exogenamente ao equilíbrio do balanço de pagamentos por fatores associados à oferta. 
Daí, portanto, a oportunidade da utilização de técnicas de cointegração na estimação direta de uma versão completa da equação de equilíbrio do balanço de pagamentos. Enquanto o vetor de cointegração fornece a relação de longo prazo existente entre as variáveis de interesse, os coeficientes de ajustamento permitem a análise das variáveis que se ajustam no curto prazo para o retorno a essa relação de longo prazo. Além disso, uma vez que as séries envolvidas são potencialmente nãoestacionárias, o instrumental de cointegração contorna os já conhecidos problemas da regressão espúria.

Especificamente, adotaremos a seguinte especificação de equilíbrio externo:

$$
P_{d} X-P_{d} R+K=P_{f} M E
$$

onde $X$ é a quantidade de exportações de bens e serviços não-fatores, $P_{d}$ é o preço das exportações em moeda nacional, $R$ é o pagamento de rendas do capital (ou seja, a renda líquida enviada ao exterior), $K$ é a entrada líquida de capitais (ou seja, o saldo em transações correntes com o sinal invertido), $M$ é a quantidade de importações de bens e serviços não-fatores, $P_{f}$ é o preço das importações em moeda estrangeira e $E$ é a taxa de câmbio nominal. Por sua vez, assumiremos as funções de demanda por importações e exportações tradicionais dadas por (3) e (4). Substituindo essas funções na equação (13) e aplicando o logaritmo natural, obtemos:

$$
\ln Y=\frac{\ln X}{\pi}+\frac{\ln (K-R)}{\pi}-\left[\frac{\psi+1}{\pi}\right] \ln \left(P_{f}+E-P_{d}\right)
$$

\subsection{Dados}

A eq. (14) foi estimada via técnicas de cointegração para dados anuais da economia brasileira entre 1930 e 2004. Os dados foram coletados na base de dados do Ipeadata. ${ }^{7}$ Quanto à construção da série de câmbio real $\left(E P_{f} / P_{d}\right)$, conforme os termos descritos na eq. (1), utilizou-se como medida para $P_{f}$ os comercializáveis norte-americanos (IPA-EUA) e, para $P_{d}$, os não-comercializáveis locais (IPC-FIPE), de maneira que adotamos a medida de câmbio real mais tradicionalmente utilizada. Além disso, posto que o componente financeiro assume valores tanto positivos como negativos, fazemos uso da seguinte aproximação local para o cálculo do logaritmo dessa variável:

$$
\ln (K-\mathrm{R})=[(\mathrm{K}-\mathrm{R}) / \operatorname{Média}(\mathrm{K}-\mathrm{R})]-1
$$

\subsection{Testes de raiz unitária}

Para estimar a equação (14) por técnicas de cointegração via metodologia de Johansen, é necessário que as séries envolvidas sejam integradas de ordem 1. Assim, o primeiro passo consistiu na

7 Para os dados de balanço de pagamentos entre 1947-2004, a fonte original é o Banco Central do Brasil. Já para o período entre 1930-1946, o IPEA compilou dados de diversos autores. Todas as séries de balanço de pagamentos em dólares foram deflacionadas pelo IPC norte-americano. A série de câmbio nominal entre 1942-2004 tem como fonte original o Banco Central do Brasil. Para o período entre 1930-1942, por sua vez, o IPEA compilou dados de diversos autores. As séries de produto interno bruto a preços constantes e formação bruta de capital fixo a preços constantes entre 1947-2004 têm como fonte original o BNDES. Para o período entre 1930-1947, por sua vez, a série foi elaborada pelo próprio IPEA. 
realização dos testes de raiz unitária para as variáveis envolvidas. Foram feitos os testes de Dickey Pantula (que testa 2 raízes unitárias contra 1), ADF, e KPSS. Este último, ao inverter a hipótese nula, minimiza o problema de baixa potência do teste ADF. Os resultados estão reportados no Anexo 1.

Verificamos que renda real, exportações reais e câmbio real têm uma raiz unitária. Por todos os testes realizados, porém, concluímos que o componente financeiro $(K-R)$ é estacionário. Como coloca Johansen (1995, p. 74), porém, se existem duas ou mais variáveis integradas de ordem 1, a cointegração ainda é válida, mesmo se existir uma variável estacionária. Logo, prosseguiremos com a análise de cointegração.

\subsection{Vetor de Correção de Erro}

Foram feitos os testes tradicionais de cointegração. Foi escolhido um VAR de ordem 2, o que equivale a um VEC de ordem 1, tendo em vista os critérios LR e FPE, reportados no Anexo 2. Escolher-se-á um modelo sem termos deterministas, com o objetivo de impor a satisfação do equilíbrio externo no longo prazo, conforme reportado no Anexo 2. Com essa especificação, foram feitos os tradicionais testes de cointegração, estatísticas do traço e autovalor. É importante observar que a análise dos resíduos da cointegração nos aponta alguns problemas de normalidade nas variáveis câmbio real e componente financeiro, algo que esperamos ser solucionado com a utilização de uma amostra razoavelmente grande.

Como resultado, obtivemos o seguinte vetor de correção de erro:

Vetor de Correção de Erro

\begin{tabular}{lcccc}
\hline & Vetor de Cointegração - Relação de Longo Prazo \\
\hline Renda Interna & 1,000000 & & \\
Exportações & $-0,865604$ & & \\
& {$[-17,9048]$} & & & \\
Comp. Financeiro & 0,086866 & & & \\
& {$[1,49677]$} & & & \\
Câmbio Real & 0,799211 & & & \\
& {$[0,90581]$} & Export & C Financ & Câmbio \\
\hline & Mecanismo de Correção de Erro - Coeficientes de Ajustamento & $-0,012658$ \\
\hline & $-0,012119$ & $-0,001506$ & {$[-1,28634]$} & {$[-0,91014]$} \\
\hline
\end{tabular}

\subsection{Análise dos resultados}

Conforme os resultados acima, a única variável significante na relação de longo prazo é aquela que representa as exportações. O componente financeiro só seria significante a $20 \%(10 \%$ 
unicaudal) e contribuiria negativamente para o produto. Os termos de intercâmbio, por sua vez, são não significantes. Logo, no equilíbrio externo de longo prazo, as variáveis que se cointegram com significância são as exportações e a renda, enquanto o componente financeiro e os termos de troca não têm um papel relevante nesse equilíbrio de longo prazo, o que já é uma corroboração importante à abordagem do crescimento sob restrição externa.

Ainda mais interessante, porém, é a análise dos coeficientes de ajustamento. O único coeficiente de ajustamento diferente de zero é o da renda real, sendo seu sinal o esperado, ou seja, a renda é a única variável que se moveria no curto prazo para retornar ao equilíbrio de longo prazo.

As exportações, a taxa de câmbio real e o componente financeiro podem ser considerados fracamente exógenos, ou seja, nenhum deles é responsável pelo retorno à situação de equilíbrio externo. Em outras palavras, se algum choque atinge o equilíbrio externo, a variável que se ajustará na direção e extensão necessárias para restaurar aquele equilíbrio externo é a renda real. No longo prazo, por conseguinte, a renda interna é endógena ao equilíbrio externo, uma evidência empírica que fornece forte corroboração à abordagem do crescimento sob restrição externa à Thirlwall para o caso brasileiro.

Dado que as exportações, o câmbio real e o componente financeiro são considerados fracamente exógenos, ou seja, o seu coeficiente de ajustamento não é estatisticamente diferente de zero, podemos fazer um teste de Casualidade de Granger para verificar se tais variáveis podem ser consideradas fortemente exógenas. Esses testes são reportados no Anexo 3. As exportações são fracamente exógenas e podem ser consideradas fortemente exógenas a 5\%. Isso implica que as exportações não são Granger-causadas, a tal nível de significância, seja pela renda, seja pelo componente financeiro, seja pelo câmbio real.

Portanto, esses resultados invalidariam, ao menos para o Brasil, a 5\% de significância, a análise de Krugman (1989) de que o ajuste do balanço de pagamentos ocorreria por meio do ajuste da elasticidade das exportações, que reagiriam a variações na renda. Se a análise de Krugman valesse para o Brasil, necessariamente as exportações (nas quais está embutida a elasticidade-renda das exportações) necessariamente deveriam responder à mudanças na renda interna, o que não ocorre.

O componente financeiro também é fortemente exógeno, não sendo causado por nenhuma das demais variáveis. Esse resultado parece corroborar a hipótese de que o influxo de capitais aos países emergentes responde mais às condições de liquidez internacional do que aos indicadores externos e internos desses países. É claro que, para comprovar essa hipótese, seriam necessárias outras considerações que fogem do escopo deste artigo. No entanto, essa exogeneidade do componente financeiro ao equilíbrio externo sugere a validade da investigação dessa hipótese.

A taxa de câmbio real, para o período analisado, também pode ser considerada fortemente exógena, não sendo Granger-causada seja pela renda interna, seja pelas exportações, seja pelo componente financeiro. Para entender esse resultado, porém, devemos lembrar que o nosso período de análise é bastante longo, contemplando da década de 1930 a 2004. Ao longo desse período, a política cambial foi, muitas vezes, um importante instrumento de política econômica. Dado que foram inúmeros os regimes de câmbio que vigoraram ao longo desse período, a associação automática entre taxa de câmbio e componente financeiro parece se basear muito mais na experiência recente que em um período mais longo de análise como o adotado neste artigo. 


\subsection{Investigação de um mecanismo de transmissão}

Em seguida, este artigo se propôs a dar um passo além da corroboração da abordagem do crescimento sob restrição externa à Thirlwall, desenvolvendo uma primeira análise de um mecanismo de transmissão entre o setor externo e o produto para o caso brasileiro. Conforme McCombie e Thirlwall (1994), o fato de o crescimento econômico de longo prazo estar sujeito à restrição externa pode implicar o seguinte círculo vicioso: "if a country gets into balance-of-payments difficulties as it expands demand before the short-term capacity growth is reached, then demand must be curtailed; supply is never fully utilised; investment is discouraged; technological progress is slowed down, and a country's goods compared with foreign goods become less desirable so worsening the balance of payments still further, and so on. A vicious circle is started. By contrast, if a country is able to expand demand up to the level of existing productive capacity, without balance-of-payments difficulties arising, the pressure of demand upon capacity may well raise the capacity growth rate." (p. 233).

Já vimos que existe uma relação de longo prazo entre o equilíbrio externo e a renda interna, sendo que a renda se ajusta na direção e extensão necessárias para a obtenção do equilíbrio externo. Vejamos agora a relação existente - se alguma existe - entre a renda interna e o investimento. Para tanto, estimamos, via cointegração, a relação entre renda real e formação bruta de capital fixo (FBCF). Os dados compreendem o mesmo período (1930-2004), sendo utilizada a mesma fonte.

Novamente, o primeiro passo consiste em verificar, por meio dos testes de Raiz Unitária, se todas as séries podem ser consideradas integradas de ordem 1. Os resultados, reportados no Anexo 1, apontam que ambas as séries são não-estacionárias, permitindo, assim, a utilização da cointegração. Com base nos critérios LR, FPE, AIC e HQ, foi estimado um VEC de ordem 1. Quanto aos termos deterministas, o Princípio de Pantula apontou para um modelo com constante dentro e fora do vetor de cointegração e tendência dentro do vetor de cointegração. Os resultados estão reportados no Anexo 6.

Obtivemos o seguinte vetor de correção de erro:

Vetor de Correção de Erro

\begin{tabular}{|c|c|c|}
\hline \multicolumn{3}{|c|}{ Vetor de Cointegração - Relação de Longo Prazo } \\
\hline Renda Interna & 1,000000 & \\
\hline \multirow[t]{2}{*}{ FBCF } & $-0,783026$ & \\
\hline & {$[-7,62070]$} & \\
\hline \multirow[t]{2}{*}{ @Tendência } & $-0,006416$ & \\
\hline & {$[-0,91141]$} & \\
\hline Constante & $-6,757847$ & \\
\hline \multicolumn{3}{|c|}{ Mecanismo de Correção de Erro - Coeficientes Ajustamento } \\
\hline & Renda & FBCF \\
\hline & $-0,033098$ & 0,164915 \\
\hline & {$[-1,45058]$} & {$[2,67628]$} \\
\hline
\end{tabular}

O vetor acima pode ser escrito na seguinte forma: 


$$
\mathrm{Y}=6,8+0,78 \mathrm{FBCF}+0,006 \mathrm{t}
$$

Ou seja, existe uma relação positiva e significativa entre renda e FBCF (formação bruta de capital fixo). Além disso, a relação de casualidade parece ser exatamente a sugerida por McCombie e Thirlwall (1994), ou seja, a renda se ajusta ao equilíbrio externo e o investimento responde à renda.

Na estimação do Vetor de Correção de Erro, notamos que os coeficientes de ajustamento têm o sinal esperado, mas o coeficiente da renda pode ser considerado igual a zero, ou seja, a renda não se ajusta no curto prazo para voltar ao equilíbrio entre renda e investimento. Vale dizer, todo o ajuste ocorre por meio da variável investimento. Assim sendo, a renda pode ser considerada fracamente exógena. Fizemos também um teste de casualidade de Granger que corroborou essa análise, porquanto a renda não é Granger-causada pelo investimento, ou seja, a renda é fortemente exógena. Assim, o investimento é Granger-causado pela renda, enquanto a renda não é Granger-causada pelo investimento e sim, de acordo com os resultados anteriores, pelo setor externo. ${ }^{8}$

\section{CONSIDERAÇÕES FINAIS}

O presente artigo detectou que, de uma perspectiva de longo prazo, o nível de atividade da economia brasileira tem sido determinado essencialmente pelas condições associadas ao equilíbrio das contas externas. Admitindo-se a variabilidade dos termos de troca e a presença de fluxos de capital, detectou-se que, no equilíbrio externo de longo prazo, as variáveis que se cointegram com significância são as exportações e a renda, enquanto o componente financeiro e os termos de troca não têm um papel relevante. Igualmente interessante foi a análise dos coeficientes de ajustamento. O único coeficiente de ajustamento diferente de zero é o da renda real, sendo seu sinal o esperado, ou seja, a renda é a única variável que se moveria no curto prazo para retornar ao equilíbrio de longo prazo. As exportações, a taxa de câmbio real e o componente financeiro podem ser considerados fracamente exógenos, ou seja, nenhum deles é responsável pelo retorno à situação de equilíbrio externo. Uma vez que as exportações, o câmbio real e o componente financeiro são considerados fracamente exógenos, fizemos um teste de Casualidade de Granger para verificar se tais variáveis podem ser consideradas fortemente exógenas. As exportações são fracamente exógenas e não são Granger-causadas seja pela renda, seja pelo componente financeiro, seja pelo câmbio real.

Em seguida, desenvolvemos uma análise de um possível mecanismo de transmissão - o investimento - entre o setor externo e o produto. Posto que já havíamos detectado que existe uma relação de longo prazo entre o equilíbrio externo e a renda interna, sendo que a renda se ajusta na direção e extensão necessárias para a obtenção do equilíbrio externo, tratava-se, então, de avaliar a existência de alguma relação entre a renda interna e o investimento. Com efeito, detectou-se a existência de uma relação positiva e significativa entre a renda e a formação bruta de capital fixo. Além

8 Uma ampliação do horizonte de compreensão do(s) mecanismo(s) de transmissão subjacente(s) à operação da restrição externa ao crescimento econômico brasileiro se beneficiaria da estimação da versão desagregada da Lei de Thirlwall derivada em Araujo e Lima (2007). Derivada a partir de um arcabouço macrodinâmico multissetorial Pasinettiano, essa versão indica que o crescimento da renda per capita é diretamente proporcional ao crescimento das exportações, sendo essa proporção inversamente (diretamente) relacionada com as elasticidades-renda setoriais das importações (exportações) ponderadas pela participação de cada setor no total correspondente. 
disso, a relação de casualidade parece ser exatamente aquela sugerida na literatura de crescimento sob restrição externa, ou seja, a renda se ajusta ao equilíbrio externo e o investimento responde à renda. Em termos de ajustamento, percebeu-se que os coeficientes têm o sinal esperado, mas o coeficiente da renda pode ser considerado igual a zero, ou seja, a renda não se ajusta no curto prazo para voltar ao equilíbrio entre renda e investimento. Vale dizer, todo o ajuste ocorre por meio da variável investimento. Assim, a renda pode ser considerada fracamente exógena. Fizemos também um teste de casualidade de Granger que corroborou essa análise, porquanto a renda não é Grangercausada pelo investimento, ou seja, a renda é fortemente exógena. O investimento é Granger-causado pela renda, enquanto a renda não é Granger-causada pelo investimento.

Neste contexto, a obtenção recorrente de saldos comerciais expressivos é o mecanismo mais efetivo de conciliação do crescimento econômico com o equilíbrio das contas externas. Afinal, um desempenho exportador adequado não somente alivia as restrições externas ao crescimento econômico, mas, inclusive, à maneira de um círculo virtuoso, funciona como um propulsor fundamental deste. Logo, o necessário processo de substituição de importações, impulsionado que é pelo próprio crescimento econômico, deve desdobrar, tanto quanto possível, em aumento na produção nacional de bens comercializáveis internacionalmente (Lima 2005).

De maneira mais ampla, cabe reconhecer que aspectos e dimensões relativas ao impacto do comércio exterior sobre os níveis de utilização e crescimento da capacidade produtiva não esgotam o conjunto de elementos envolvidos na questão da aceleração sustentável do crescimento econômico brasileiro. Porém, são considerações que merecem ser contempladas, analítica e empiricamente, nas discussões acerca de soluções duradouras para um problema recorrente na experiência nacional de desenvolvimento: a geração de desequilíbrio nas contas externas quando se acelera por algum tempo o ritmo da demanda agregada.

\section{REFERÊNCIAS}

ALONSO, JOSÉ A.; GARCIMARTÍN, C. A new approach to balance-of-payments constraint: some empirical evidence. Journal of Post Keynesian Economics, v. 21, n. 2, 1998-99.

ANDERSEN, P. S. The 45-degree rule revisited. Applied Economics, 25, 1993.

ANSARI, H.; XI, Y. The chronicle of economic growth in southeast asian countries: does Thirlwall's Law provide an adequate explanation. Journal of Post Keynesian Economics, 224, Summer 2000.

ARAUJO, R. A.; LIMA, G. T. A structural economic dynamics approach to balance-of-payments-constrained growth, Cambridge Journal of Economics, 315, p. 755-774, 2007.

ATESOGLU, H. S. Balance of payments determined growth in Germany. Applied Economic Letters, 16, 1994.

. Balance-of-payments-constrained growth model and implications for the United States. Journal of Post Keynesian Economics, 193, Spring 1997.

BACHA, E. L. Um modelo de três hiatos. Pesquisa e Planejamento Econômico, v. 19, n. 2, ago. 1989.

. A three-gap model of foreign transfers and the GDP growth rate in developing countries. Journal of Development Economics, v. 32, n. 2, 1990. 
BAIRAM, E. Balance of payments, the Harrod foreign multiplier and economic growth: the european and north american experience. Applied Economics, 20, 1988.

; DEMPESTER, G. The Harrod foreign multiplier and economic growth in asian countries. Applied Economics, 2311, 1991.

BARBOSA-FILHO, N. The balance-of-payments constraint: from balanced trade to sustainable debt. Banca Nazionale del Lavoro Quarterly Review, n. 219, Dec. 2001.

BÉRTOLA, L., HIGACHI, H.; PORCILE, G. Balance-of-payments-constrained growth in Brazil: a test of Thirlwall's Law, 1890-1973. Journal of Post Keynesian Economics, v. 25, n. 1, 2002.

CHENERY, H.; BRUNO, M. Development alternatives in an open economy: the case of Israel. Economic Journal, 57, 1962.

ELLIOT, D.; RHODD, R. Explaining growth rate differences in highly indebted countries: an extension to Thirlwall and Hussain. Applied Economics, 31, 1999.

FERREIRA, A. A lei de crescimento de Thirlwall. Dissertação (Mestrado) - IE, Unicamp, 2001. Mimeografado.

HARROD, R. International economics. Cambridge: Cambridge University Press, 1933.

HIEKE, H. Balance-of-payments-constrained growth: a reconsideration of the evidence for the U.S. economy. Journal of Post Keynesian Economics, v. 19, n. 3, 1997.

HOLLAND, M., VIEIRA, F.; CANUTO, O. Economic growth and the balance-of-payments constraint in Latin America. Investigación Económica, v. LXIII, 247, 2004.

HUSSAIN, M. N. The balance-of-payments constraint and growth rate differences among African and East Asian economies. African Development Review, June 1999.

JAYME JR., F. G. Balance-of-payments-constrained economic growth in Brazil. Revista de Economia Política, v. 23, jan./mar. 2003.

JOHANSEN, S. Likelihood-based inference in cointegrated vector autoregressive models. Oxford: Oxford University Press, 1995.

KALDOR, N. The case for regional policies. Scottish Journal of Political Economy, Nov. 1970.

KRUGMAN, P. Differences in income elasticities and trends in real exchange rates. European Economic Review, 33, 1989.

McCOMBIE, J.; THIRLWALL, A. Essays on balance of payments constrained growth - theory and evidence. London: Routledge2004

ROUTLEDGE, P. Differences in income elasticities and trends in real exchange rates. European Economic Review, 33, 1989.

LÉON-LEDESMA, M. An application of Thirlwall's Law to the spanish economy. Journal of Post Keynesian Economics, v. 21. 1999.

LIMA, G. T. Restrição externa e investimento direto estrangeiro no Brasil. In: SOBREIRA, R.; RUEDIGER, M. A. (Org.) Desenvolvimento e construção nacional: política econômica. Rio de Janeiro: Editora da FGV, 2005.

LOPEZ, J.; CRUZ, A. Thirlwall's Law and beyond: the Latin American Experience. Journal of Post Keynesian Economics, v. 22, n. 3, Spring 2000.

McCOMBIE, J. Thirlwall's Law and balance of payments coinstrained growth: A comment on the debate. Applied Economics, 21, 1989. 
. On the empirics of balance-of-payments-constrained growth. Journal of Post Keynesian Economics, v. 19, n. 3, 1997.

.; THIRLWALL, A. Economic growth and the balance of payments constraint, New York: St. Martin's Press. 1994. cap. 3.

. Economic growth and balance-of-payments constraint revisited. In: ARESTIS, P., PALMA, G.; SĀWYER, M. (Ed.) Markets, unemployment and economic policy. London: Routledge, 1997. v. 2. 2004.

Essays on balance of payments constrained growth - theory and evidence. London: Routledge,

MORENO-BRID, J. C. On capital flows and the balance-of-payments constrained growth model. Journal of Post Keynesian Economics, v. 21, 1998-99.

. Mexico's economic growth and the balance-of-payments constraint: a cointegration analysis. International Review of Applied Economics, 132, May 1999.

. Capital flows, interest payments and the balance-of-payments constrained growth model: a theoretical and an empirical analysis. Metroeconomica, v. 54, n. 2, May 2003.

; PÉREZ, E. Balance-of-payments constrained growth in Central America. Journal of Post Keynesian Economics, 221, Fall 1999.

PERRATON, J. Balance of payments constrained growth and developing countries: an examination of Thirlwall's hypothesis. International Review of Applied Economics, 117, 2003.

PREBISCH, R. The economic development of latin america and its principal problems. ECLA, New York, 1950.

RAZMI, A. Balance of payments constrained growth model: the case of India. Amherst: University of Massachusetts, 2005. (Working Paper, 05)

SANTOS, A. T. L., LIMA, G. T.; CARVALHO, V. R. A restrição externa como fator limitante do crescimento econômico brasileiro: um teste empírico. XXXIII ENCONTRO NACIONAL DE ECONOMIA, Natal. Anais Eletrônicos do XXXIII Encontro Nacional de Economia, dez. 2005. Disponível em: <http://www.anpec.org.br>.

SEERS, D. A model of comparative growth rates of the world economy. Economic Journal, Mar. 1962.

THIRLWALL, A. The balance of payments constraint as an explanation of international growth rates differences. Banca Nazionale del Lavoro Quarterly Review, v. 128, 1979.

. Foreign trade elasticities in centre-periphery models of growth and development. Banca Nazionale $\bar{d} \bar{e} \bar{L}$ Lavoro Quarterly Review, Sept. 1983.

. Reflections on the concept of balance-of-payments-constrained growth. Journal of Post Keynesian Economics, v. 19, n. 3, 1997.

; HUSSAIN, M. The balance of payments constraint, capital flows and growth rates differences between developing countries. Oxford Economic Papers, v. 34, 1982. 


\section{ANEXo 1 - TESTES DE RAIZ UNITÁRIA}

\section{Teste Dickey Pantula (teste de 2 raízes unitárias contra 1 raiz unitária)}

\begin{tabular}{lccccc}
\hline & Termos Determ. & Defasagem & t-calc. & t-tab. & Conclusão \\
\hline Renda & nada & 0 & $-3,98$ & $-1,95$ & Rejeição de 2 RU \\
Câmbio & nada & 0 & $-7,37$ & $-1,95$ & Rejeição de 2 RU \\
Exportações & nada & 1 & $-7,37$ & $-1,95$ & Rejeição de 2 RU \\
FBCF & Cte. & 1 & $-5,25$ & $-2,90$ & Rejeição de 2 RU \\
\hline
\end{tabular}

Conclusão: em todos os casos rejeitamos a hipótese de 2 raízes unitárias.

\section{Testes $\mathrm{ADF}$ - 1 raiz unitária contra 0 raiz unitária}

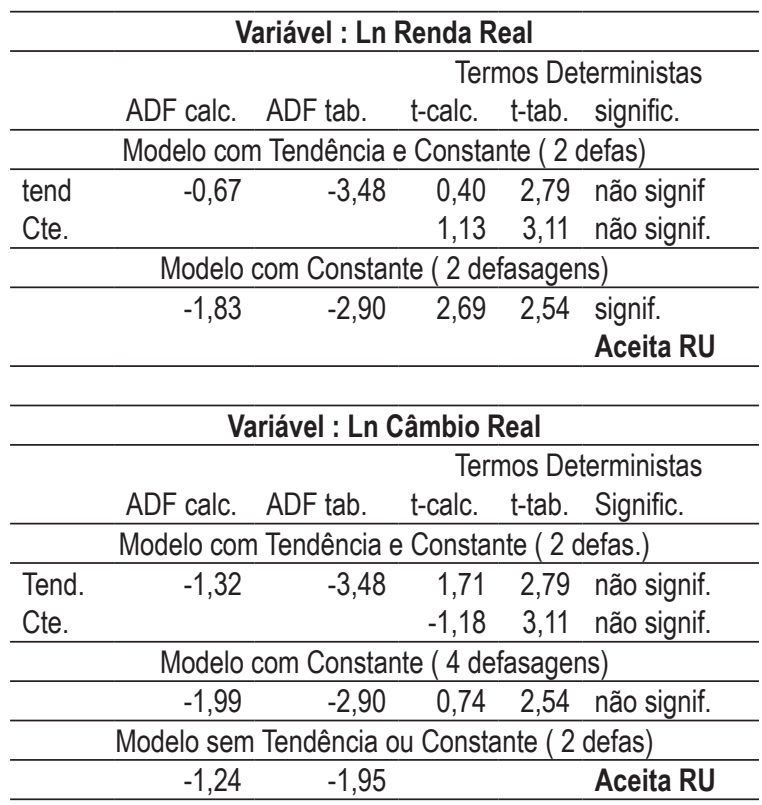

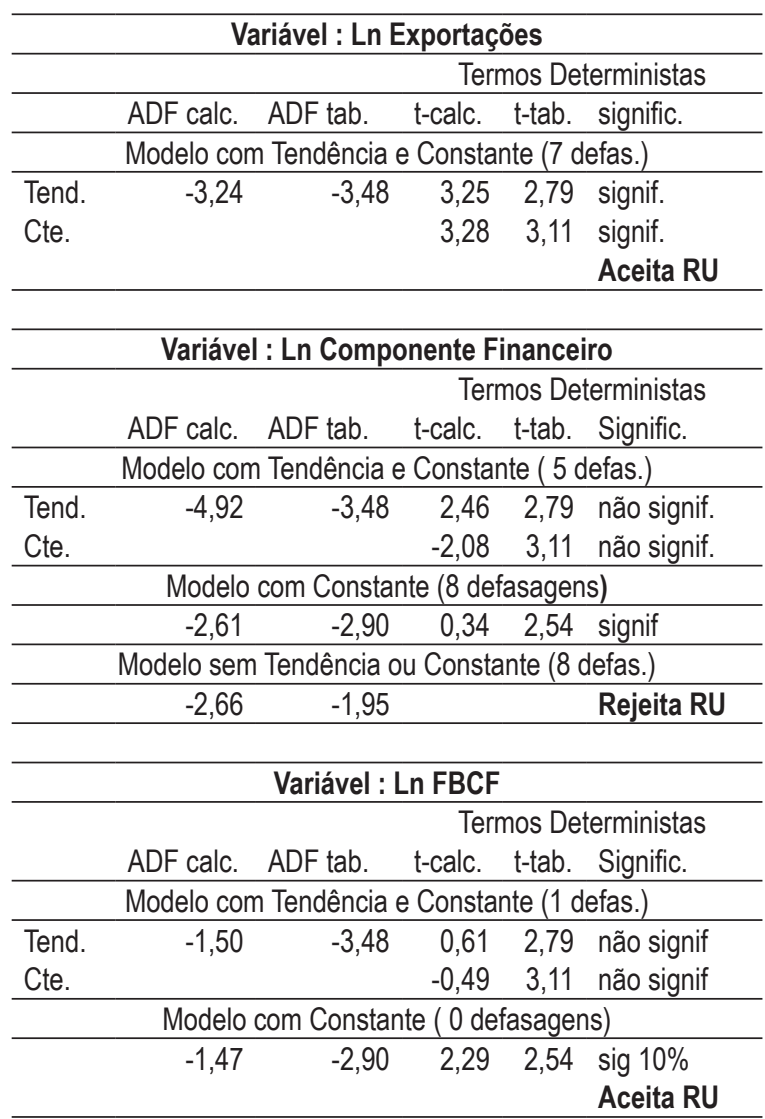

Obs: valores críticos a 5\% de significância. Valores críticos dos termos deterministas para amostras de 100 observações.

Conclusão: podemos aceitar a hipótese de 1 raiz unitária para as variáveis Exportações, Renda Interna, Câmbio Real e FBCF. Rejeitamos a hipótese de 1 RU para a variável componente financeiro, indicando que esta série é estacionária. 


\section{Teste KPSS - zero raiz unitária contra 1 raiz unitária}

\begin{tabular}{lccccc}
\hline Modelo & Câmbio & Renda & Exportações & Financeiro & FBCF \\
\hline Tendência & 0,204 & 0,212 & 0,073 & 0,051 & 0,261 \\
Conclusão & $1 \mathrm{RU}$ & $1 \mathrm{RU}$ & $\mathbf{0 R U}$ & $\mathbf{R U}$ & $1 \mathrm{RU}$ \\
Constante & 0,211 & 1,160 & 1,130 & 0,165 & 1,11 \\
Conclusão & $\mathbf{0} \mathrm{RU}$ & $1 \mathrm{RU}$ & $1 \mathrm{RU}$ & $\mathbf{0} \mathrm{RU}$ & $1 \mathrm{RU}$ \\
Conclusão Final & $1 \mathrm{RU}$ tend. & $\mathbf{1} \mathrm{RU}$ & $\mathbf{R U}$ cte. & $\mathbf{0} \mathrm{RU}$ & $1 \mathrm{RU}$ \\
\hline
\end{tabular}

Obs.: O teste KPSS foi realizado com 6 defasagens para todas as variáveis, exceto no caso do componente financeiro, em que foram 5 defasagens.

Conclusão: novamente, apenas para o componente financeiro podemos rejeitar que existe Raiz Unitária para qualquer especificação do modelo.

\section{ANEXo 2 - Vetor DE CORREÇÃo DE ERro}

\section{Seleção da ordem de defasagem do VAR}

Critérios de seleção da ordem de defasagem do VAR

Variáveis endógenas: LYR, LX, LFINM2, LER

Amostra: 1930-2004

\begin{tabular}{ccccccc}
\hline Defasagem & LogL & LR & FPE & AIC & SC & HQ \\
\hline 0 & -373.4111 & NA & 0,662292 & 10,93945 & 11,06896 & 10,99083 \\
1 & 26,15637 & 741,2266 & $9,84 \mathrm{E}-06$ & $-0,178446$ & $\mathbf{0 , 4 6 9 1 2 2 ^ { * }}$ & $\mathbf{0 , 0 7 8 4 6 6 ^ { * }}$ \\
2 & 43,26765 & $\mathbf{2 9 , 7 5 8 7 4 ^ { * }}$ & $\mathbf{9 , 5 8 E - 0 6 ^ { * }}$ & $-0,210656$ & 0,954964 & 0,251784 \\
3 & 59,41920 & 26,21702 & $9,65 \mathrm{E}-06$ & $\mathbf{- 0 , 2 1 5 0 4 9 ^ { * }}$ & 1,468625 & 0,452920 \\
\hline
\end{tabular}

LR: Teste estatístico LR seqüencial modificado (cada teste ao nível de 5\%).

FPE: Erro de Predição Final.

AIC: Critério de Informação de Akaike.

SC: Critério de Informação de Schwarz.

HQ: Critério de Informação de Hannan-Quinn.

Conclusão: os critérios de informação e o teste LR forneceram informações contraditórias sobre a ordem do VAR a ser escolhido. Escolhemos então o critério FPE e LR (VEC 1), pois além de apresentar um número de defasagens intermediárias, nos permitirá fazer o teste de Casualidade de Granger, o que não seria possível se escolhêssemos o VEC 0 apontado pelo teste SC e HQ. 


\section{Escolha dos termos deterministas}

Séries: LYR, LX, LFINM2, LER

\begin{tabular}{lccccc}
\hline Tendência: & Nenhuma & Nenhuma & Linear & Linear & Quadrática \\
\hline Rank ou & Sem Intercepto & Intercepto & Intercepto & Intercepto & Intercepto \\
\# CEs & Sem Tend. & Sem Tend. & Sem Tend. & Tendência & Tendência \\
\hline \multicolumn{7}{c}{ Número selecionado (nível de 5\%) de relações de cointegração (colunas) } \\
Max-Eig & 2 & 1 & 0 & 0 & 0 \\
\hline
\end{tabular}

Conclusão: pelos critérios tradicionais, poder-se-ia escolher o segundo modelo com constante dentro do vetor de cointegração, pois as variáveis têm unidades diferenciadas, sendo o que nos indicaria o Princípio de Pantula para obter ao menos 1 vetor de cointegração. No entanto, propositalmente pela especificação do modelo, forçaremos que não haja constante dentro do vetor de cointegração, pois desta forma imporíamos o equilíbrio do balanço de pagamentos no longo prazo. Temos, então, pelas estatísticas de traço e autovalor, dois vetores de cointegração, dos quais apenas o primeiro tem algum sentido econômico.

\section{Anexo 3 - Testes das VAriáveis de Ajuste e Casualidade de Granger}

\section{Teste LR dos Coeficientes de Ajustamento}

- Coeficiente de ajustamento da renda

Estimativas do Vetor de Correção de Erro

Restrições de Cointegração:

\begin{tabular}{lr}
$A(1,1)=0$ & \\
\hline Teste $L R$ para as restrições (rank = 1): & 7,256494 \\
Qui-quadrado(1) & 0,007065 \\
Probabilidade &
\end{tabular}

- Coeficiente de ajustamento das exportações

Estimativas do Vetor de Correção de Erro

Restrições de Cointegração:

\begin{tabular}{ll}
$\mathrm{A}(2,1)=0$ & \\
\hline Teste LR para as restrições (rank = 1): & \\
Qui-quadrado(1) & 0,025573 \\
Probabilidade & 0,872949
\end{tabular}


- Coeficiente de ajustamento do financeiro

Estimativas do Vetor de Correção de Erro

Restrições de Cointegração:

$\mathrm{A}(3,1)=0$

Teste $L R$ para as restrições (rank $=1$ ):

Qui-quadrado(1)

0,640682

Probabilidade

0,423464

- Coeficiente de ajustamento do câmbio

Estimativas do Vetor de Correção de Erro

Restrições de Cointegração:

$\mathrm{A}(4,1)=0$

Qui-quadrado(1)

0,733425

Probabilidade

0,391775

Conclusão: o único coeficiente de ajustamento diferente de 0 é o da renda, tendo o sinal esperado. Exportações, câmbio real e o componente financeiro podem ser considerados fracamente exógenos.

\section{Teste de Casualidade de Granger}

Causalidade à Granger

\begin{tabular}{lccc}
\hline & & Exportações & \\
\hline Excl. & Qui-quadrado & df & Probabilidade \\
\hline Renda & 3,789834 & 1 & 0,0516 \\
Comp Financ. & 2,473971 & 1 & 0,1157 \\
Câmbio & 0,546311 & 1 & 0,4598 \\
\hline Todos & 6,160456 & 3 & 0,1041 \\
\hline & \multicolumn{2}{c}{ Componente Financeiro } & Probabilidade \\
\hline Excl. & Qui-quadrado & df & 0,5085 \\
\hline Renda & 0,437183 & 1 & 0,1531 \\
Export. & 2,041392 & 1 & 0,7039 \\
Câmbio & 0,144477 & 1 & 0,3273 \\
\hline Todos & 3,450332 & 3 & Probabilidade \\
\hline & & & 0,5494 \\
\hline Excl. & Qui-quadrado & df & 0,5993 \\
\hline Renda & 0,358413 & 1 & 0,2063 \\
Export. & 0,275991 & 1 & 0,4343 \\
Comp Financ. & 1,597279 & 3 & 1 \\
\hline Todos & 2,735053 & 3 & 1 \\
\hline
\end{tabular}

Conclusão: As exportações são fracamente exógenas, podendo ser vistas como fortemente exógenas a 5\%. Isso implica que as exportações não são Granger-causadas seja pela renda, seja pelo componente financeiro, seja pelo câmbio a este nível de significância. O componente financeiro e o câmbio podem ser considerados fortemente exógenos, não sendo causados por nenhuma das variáveis. 


\section{ANEXo 4 - Vetor CoRreÇÃo de ERRO - FBCF E RENDA}

\section{Determinação da ordem do VAR}

Critérios de seleção da ordem de defasagem do VAR

Variáveis endógenas: LYR, LFBCF

\begin{tabular}{ccccccc}
\hline Defasagem & LogL & LR & FPE & AIC & SC & HQ \\
\hline 0 & $-103,6355$ & NA & 0,076626 & 3,106927 & 3,172207 & 3,132793 \\
1 & 206,7223 & 593,3311 & $9,36 \mathrm{E}-06$ & $-5,903597$ & $-5,707758^{*}$ & $-5,825999$ \\
2 & 214,2277 & $13,90707^{*}$ & $8,45 \mathrm{E}-06^{*}$ & $-6,006697^{*}$ & $-5,680298$ & $-5,877368^{*}$ \\
3 & 216,3634 & 3,831746 & $8,93 \mathrm{E}-06$ & $-5,951865$ & $-5,494908$ & $-5,770804$ \\
\hline
\end{tabular}

Conclusão: a maioria dos critérios indica um VAR 2, ao qual corresponde um VEC 1.

\section{Termos Deterministas}

Amostra: 1930-2004

Observações incluídas: 73

Séries: LYR, LFBCF

Intervalos de defasagem: 1 para 1

\begin{tabular}{lccccc}
\hline Tendência: & Nenhuma & Nenhuma & Linear & Linear & Quadrática \\
\hline Rank ou & Sem Intercepto & Intercepto & Intercepto & Intercepto & Intercepto \\
\# CEs & Sem Tendência & Sem Tendência & Sem Tendência & Tendência & Tendência \\
\hline \multicolumn{5}{c}{ Número selecionado (nivel de 5\%) } & de relações de cointegração (colunas) \\
\hline Traço & 2 & 2 & 2 & 1 & 1 \\
Max-Eig. & 2 & 2 & 2 & 1 & 1 \\
\hline
\end{tabular}

Conclusão: pelo principio de Pantula e pela análise gráfica das séries (não existência de tendência quadrática), optamos pela especificação com constante e tendência dentro do vetor de cointegração e com constante fora. 


\section{Anexo 5 - Testes das Variáveis de Ajuste e Casualidade de Granger}

\section{Teste LR dos coeficientes de ajustamento}

- Coeficiente de ajustamento da renda

\begin{tabular}{l}
\hline Estimativas do Vetor de Correção de Erro \\
Restrições de Cointegração: \\
$\quad A(1,1)=0$ \\
\hline Teste $L R$ para as restrições (rank = 1): \\
Qui-quadrado(1) \\
Probabilidade
\end{tabular}

Conclusão: a renda é fracamente exógena ou não se ajusta a um desequilíbrio da relação de longo prazo entre FBCF e Renda.

\section{Teste de Casualidade de Granger}

Causalidade à Granger

\begin{tabular}{|c|c|c|c|}
\hline \multicolumn{4}{|c|}{ Renda Interna } \\
\hline Excl. & Qui-quadrado & $d f$ & Probabilidade \\
\hline FBCF & 0,076826 & 1 & 0,7816 \\
\hline Todos & 0,076826 & 1 & 0,7816 \\
\hline \multicolumn{4}{|c|}{ FBCF } \\
\hline Excl. & Qui-quadrado & df & Probabilidade \\
\hline Renda & 8,434066 & 1 & 0,0037 \\
\hline Todos & 8,434066 & 1 & 0,0037 \\
\hline
\end{tabular}

Conclusão: a renda é fortemente exógena, já que não é Granger-causada pelo investimento. Logo, o investimento é Granger-causado pela renda e a renda não é Granger-causada pelo investimento. 